\title{
El derecho fundamental a la identidad cultural de los pueblos indígenas, configuración conforme el derecho internacional y perspectivas de su recepción en Chile ${ }^{1}$.
}

\author{
FUNDAMENTAL RIGHT TO THE CULTURAL IDENTITY OF INDIGENOUS PEOPLES, CONFIGURATION IN ACCORDANCE WITH \\ INTERNATIONAL LAW AND PERSPECTIVES FOR ITS RECEPTION IN CHILE
}

JUAN JORGE FAUNDES PEÑAFIEL²

RESUMEN

Se estudia el derecho fundamental a la identidad cultural de los pueblos indígenas reconocido por la Corte IDH, su naturaleza jurídica, sus fuentes y estándares jurisprudenciales. En especial, cómo se puede amparar constitucionalmente en Chile y se enuncian algunas perspectivas de impacto en la legislación interna.

ABSTRACT

We study the fundamental right to cultural identity of indigenous peoples recognized by the IACHR. We review its legal nature, sources, and its standards in the precedents. Specially, we study how the Chilean Constitution can protect this right and we enunciate some perspectives of impact on Chilean domestic legislation.

\section{PALABRAS CLAVE}

Derecho fundamental identidad cultural, pueblos indígenas, Constitución chilena

\section{KEY WORDS}

Fundamental right to cultural identity, indigenous peoples, Chilean Constitution.

\section{Introducción}

La Corte Interamericana de Derechos Humanos (Corte IDH), bajo una interpretación evolutiva de la Convención Americana de Derechos Humanos (CADH) sostiene que el derecho a la identidad cultural es un derecho fundamental y de naturaleza colectiva cuya titularidad corresponde a las comunidades y pueblos indígenas, que debe ser respetado en una sociedad multicultural, pluralista y democrática ${ }^{3}$.

En consecuencia, es posible sostener que el derecho fundamental a la identidad cultural de los pueblos indígenas (DFICPI) se ha introducido en los ordenamientos latinoamericanos y el chileno, preferentemente por medio de la acción judicial, vía Control de Convencionalidad o bajo la doctrina del Bloque de Constitucionalidad ${ }^{4}$, directo de la Corte IDH e indirecto de los tribunales nacionales ${ }^{5}$.

\footnotetext{
${ }^{1}$ Proyecto FONDECYT Iniciación N 11161079 “El derecho fundamental a la identidad cultural de los pueblos indígenas en Chile, debates y problemas a la luz de la jurisprudencia conforme al Convenio $\mathrm{N}^{\circ} 169$ de la OIT".

${ }^{2}$ Dr. Juan Jorge Faundes Peñafiel, Universidad Autónoma de Chile, Temuco, Chile, juanjorgef@gmail.com.

${ }^{3}$ Corte IDH, Pueblo Indígena Sarayaku Vs. Ecuador, de 12 de junio de 2012.

${ }^{4}$ BOGDANDY et al. (2014).

${ }^{5}$ Corte Suprema, Rol 2840-2008, de 25 de noviembre de 2009; Corte IDH, Caso Comunidad indígena Yakye Axa Vs. Paraguay, de 17 de junio de 2005; Corte IDH, Pueblo Indígena Kichwa de Sarayaku Vs. Ecuador, de 27 de junio de 2012.
} 
Asimismo, que dicho desarrollo jurisprudencial se ha articulado con la progresiva ratificación de instrumentos internacionales de derechos humanos, en el plano universal, con la propia Declaración Universal de Derechos Humanos, el Pacto de derechos Civiles y Políticos (PDCP), el Pacto de Derechos Económicos Sociales y Culturales (PIDESC), y, en especial, por instrumentos especializados como el Convenio N ${ }^{\circ} 169$ de la OIT (en adelante Convenio 169), la Declaración de Naciones Unidas de Derechos de los Pueblos Indígenas (DNUDPI), la Declaración Americana de Derechos de los Pueblos Indígenas (DADPI) y un conjunto de otros instrumentos específicos sobre el derecho a la identidad cultural ${ }^{6}$.

En Chile ha sido la jurisprudencia de sus tribunales la que -invocando el Convenio 169ha expresado en diversas sentencias consideraciones que refieren al derecho a la identidad cultural o, más bien, a "derechos culturales" o al "derecho a la cultura" de los pueblos indígenas. Solo a modo ejemplar, ha dicho la Corte Suprema que:

[...] en el sector materia de autos, existen comunidades indígenas y lugares de significación cultural, susceptibles de ser afectados [y] en dicho entendido, y considerando que la servidumbre solicitada es susceptible de afectar pueblos y personas indígenas... debió tramitarse... la consulta indígena previa $[\ldots]^{7}$

y la Corte de Apelaciones de Temuco (confirmado por la Corte Suprema) señaló que:

[...] especial atención deben tener los Estados en la protección y preservación de las tierras y culturas indígenas en todas sus manifestaciones... se agravia en su naturaleza humana y la calidad de vida y en la protección de sus sistemas de salud, puesto que el Menoko es un lugar, espacio cultural, que no debe ser molestado, sino que siempre protegido ${ }^{8}$.

Sin embargo, no se han seguido estándares sistemáticos, evidenciándose un grado de indeterminación interna del DFICPI ${ }^{9}$.

A su vez, entendemos que el desarrollo progresivo del DFICPI en el ámbito internacional, a la luz de la jurisprudencia de la Corte IDH, plantea importantes impactos y respectivos desafíos para los estados, tanto en materia de adecuación normativa, como de control de convencionalidad judicial.

En este contexto, nos hemos propuesto en este trabajo: i) abordar panorámicamente el DFICPI, su conceptualización, fundamentación normativa desde sus fuentes en el Derecho Internacional de los Derechos Humanos y en base a la propia Constitución; ii) revisar los estándares desarrollados por la jurisprudencia de la Corte IDH, como nuevo marco de obligaciones y desafíos emergentes para los ordenamientos jurídicos latinoamericanos; iii) enunciar ejemplarmente algunos campos en que el reconocimiento progresivo del DFICPI impacta el ordenamiento jurídico chileno, arrojando desafíos por enfrentar.

\footnotetext{
${ }^{6}$ Un análisis detallado y crítico de las fuentes universales descritas véase en STAVENHAGEN (2004), pp. 15-20.

${ }^{7}$ Corte Suprema, Rol 6.628-2015, de 4 de mayo de 2016, cons. 6ㅇ.

${ }^{8}$ Corte de Apelaciones de Temuco, Rol N¹773-2008, de 16 de septiembre de 2009, cons. décimo cuarto.

${ }^{9}$ CARMONA (2015), p. 984.
} 


\section{Algunas cuestiones preliminares para la comprensión de la emergencia y recepción interna del DFICPI}

En primer término, la recepción del DFICPI supone que el cumplimiento de las obligaciones internacionales del Estado en materia de derechos humanos (y derechos de los pueblos indígenas, a la luz del Convenio 169 en nuestro caso), emana de un conjunto de instrumentos internacionales de derechos humanos que operan en interacción con el derecho interno, como un cuerpo integrado y sistemático de fuentes que busca asegurar la vigencia de estos derechos nacional e internacionalmente. De esta forma, por mandato del artículo 35 del Convenio 169, la CADH en su artículo 29.b y la jurisprudencia de la Corte IDH (entendida como intérprete auténtica de acuerdo al artículo 63.3 de la $\mathrm{CADH})^{10}$, se integran hermenéuticamente otros instrumentos internacionales, tales como: como la DNUDPI, las observaciones de la CEACR de la OIT ${ }^{11}$ relativas al Convenio 169 y las recomendaciones de los relatores de Naciones Unidas sobre derechos de los indígenas, formando un estándar internacional de derechos humanos de los pueblos indígenas, un corpus iuris de hard law y soft law, que a partir de la ratificación del Convenio 169 es vinculante ${ }^{12}$.

Este enfoque supone un consenso mínimo en torno a la aplicación preferente de las normas de derechos humanos contenidas en los tratados internacionales de derechos humanos, porque estos derechos pasan a ser un auténtico límite para el ejercicio de la soberanía por parte de los organismos del Estado, conforme el artículo 5 inciso $2^{\circ}$ de la Constitución ${ }^{13}$. Entonces, en primer término, entendemos que los derechos fundamentales asegurados en los tratados internacionales en materia de derechos humanos ratificados por Chile son parte del conjunto de derechos fundamentales que asegura nuestra Constitución; y, en segundo lugar, que, constitucionalmente, estos derechos constituyen un límite para el ejercicio de la soberanía por parte del Estado ${ }^{14}$. Bajo este razonamiento, el DFICPI es exigible ante el Estado, el cual debe protegerlo y velar por su articulación con el ordenamiento jurídico interno, porque - según revisaremos-, en su tutela recae en el Estado un deber de actuación diligente ${ }^{15}$. Esta armonización debe realizarse conforme dos procesos hermenéuticos conexos, el Control de Convencionalidad (en este caso de la CADH y del Convenio № 169) y la interpretación evolutiva de los derechos humanos ${ }^{16}$. La interpretación evolutiva fue metafóricamente descrita por la Corte IDH cuando dijo que los tratados internacionales "son instrumentos vivos" que, más allá de la literalidad de sus textos, deben ser aplicados conforme el contexto y los tiempos en dicha aplicación tiene lugar ${ }^{17}$, teniendo como directriz el principio pro homine o "pro-persona". Se trata de un estándar internacional de derechos humanos que opera como "una concepción unitaria de las instancias normativas internacionales y nacionales de derechos humanos que dan un contenido material a principios constitucionales e internacionales respecto de estos derechos para resolver los casos en el fuero nacional" 18 . En síntesis, sobre la tutela del DFICPI, concordamos con la idea de la conformación de un derecho constitucional común americano para los pueblos indígenas ${ }^{19}$, en un sentido "vertical" desde la

\footnotetext{
${ }^{10}$ NOGUEIRA (2014).

${ }^{11}$ La Comisión de Expertos en Aplicación de Convenios y Recomendaciones de la OIT.

${ }^{12}$ AYLWIN et al. (2013), pp. 464-468; FAUNDES (2013), pp. 574-575.

${ }^{13}$ NOGUEIRA (1997); ALDUNATE (2010).

${ }^{14}$ Corte de Apelaciones de Rancagua, Rol N ${ }^{\circ} 103-2011$, de 14 de enero de 2013, cons. A 5.

${ }^{15}$ Corte IDH, Pueblo Indígena Xucuru y otros con Brasil (2018), cons. 188.

${ }^{16}$ NASH (2008), pp. 73, 245-246; MARTíNEZ (2013); BOGDANDY et al. (2014); HITTERS (2009).

${ }^{17}$ Corte IDH, Comunidad (Sumo) Awas Tigni Vs. Nicaragua, de 31de agosto de 2001, cons. 146.

${ }^{18} \mathrm{NASH}$ (2008), pp. 73, 245-246.

${ }^{19}$ AGUILAR (2010), pp. 9-11.
} 
influencia de la Corte IDH, pero también "horizontal", con el desarrollo progresivo de un entendimiento común regional, "en red", de las jurisdicciones domésticas ${ }^{20}$.

En segundo lugar, aunque se encuentra pendiente el reconocimiento constitucional de los pueblos indígenas en Chile, desde la mirada descrita, nada impide el ejercicio de del DFICPI en el plano interno, tanto desde sus fundamentos propiamente constitucionales, como en especial, a la luz de los tratados internacionales en materia de derechos humanos ratificados por Chile.

Una tercera cuestión corresponde a la comprensión de la "cultura" y a los diversos alcances de ella como objeto del DFICPI. En este sentido, la Declaración Universal de la Unesco sobre la identidad cultural del año 2001 define cultura como

[...] el conjunto de los rasgos distintivos espirituales y materiales, intelectuales y afectivos que caracterizan a una sociedad o a un grupo social y que abarca, además de las artes y las letras, los modos de vida, las maneras de vivir juntos, los sistemas de valores, las tradiciones y creencias $^{21}$.

En particular, respecto de los pueblos indígenas, el acercamiento a "la cultura" estará estrechamente relacionado con su cosmovisión, entendida como una trama de sentidos y significados transmitidos por símbolos, mitos, dichos, relatos, prácticas y reconstrucciones, que expresan una comprensión y reconstrucción del entendimiento de la totalidad de la existencia y de los sujetos entre sí2

Finalmente, acogemos la idea del "reconocimiento intercultural" y del "descentramiento intercultural" 23 , como puntos de partida (no del todo resueltos) para poder plantear una concepción intercultural de los derechos humanos que sustenta el DFICPI ${ }^{24}$, aunque no hacemos una revisión de las discusiones que extensamente se han planteado en la Antropología sobre los conceptos de identidad y cultura ${ }^{25}$, las cuales exceden este trabajo en extensión y enfoque.

\section{El derecho fundamental a la identidad cultural en la Constitución chilena}

La Constitución Política de Chile (CPR) no contempla en la literalidad de su texto ni el derecho a la identidad -genéricamente-, ni los derechos culturales. No obstante, argumentaremos que sí es posible fundamentar el DFICPI en la Constitución como un derecho implícito, bajo una interpretación evolutiva de la Constitución. Esto es, el reconocimiento del DFICPI supone un razonamiento hermenéutico constitucional en relación con los instrumentos internacionales en materia de derechos humanos que contemplan los derechos de los pueblos indígenas. En particular, en un ejercicio que consideramos conciliable con el sistema constitucional, de conformidad al artículo 5 inciso $2^{\circ}$ de la Constitución, estimamos se puede recepcionar el DFICPI en el ordenamiento jurídico chileno, por la vía jurisprudencial. En este sentido, ya se ha reconocido en diversos fallos chilenos el derecho a la cultura de los pueblos indígenas, con diversos alcances, como parte del derecho esencial que la Constitución asegura a todas las personas "de intervenir con

\footnotetext{
${ }^{20}$ PERRONE Y FAUNDES (2019).

${ }^{21}$ Declaración Universal de la Unesco sobre la identidad cultural del año 2001.

22 SALAS (2003), pp. 72-73.

${ }^{23}$ CLAROS Y VIAÑA (2009), pp. 117-118; FAUNDES (2017a), pp. 43-54.

${ }^{24}$ VILLEGAS Y MELLA (2017), pp. 140-150; FAUNDES (2015a).

${ }^{25}$ GRIMSON (2012); VERGARA (2012).
} 
igualdad de condiciones en su mayor realización espiritual y material posible". Para estos efectos, conjuntamente, ha invocado el Convenio 169 de la $\mathrm{OIT}^{26}$.

Ahora bien, en este apartado nos interesa desarrollar brevemente cómo este derecho constituye un derecho fundamental que es posible justificar, autónomamente, a partir de la Constitución Política, entendida en sentido material y — soslayando la mera literalidad-, desde sus valores, principios, a la luz de los derechos fundamentales ya reconocidos por la Constitución, comprensiva de derechos implícitos ${ }^{27}$.

Desde la perspectiva constitucional, el DFICPI se justifica en una visión amplia del principio de igualdad y del respeto de la dignidad humana ${ }^{28}$. En este sentido, el artículo 1 inc. $1^{\circ}$ de la Constitución Chilena dispone que "Todas las personas nacen libres e iguales en dignidad y derechos", mientras el artículo $19 \mathrm{~N}^{\circ} 2$ de la misma Carta Fundamental asegura a todas las personas "La igualdad ante la ley", lo que, en primer orden, se traduce en la prohibición de toda discriminación arbitraria. A su vez, este principio igualitario debe entenderse a la luz de lo dispuesto en el inciso final del mismo artículo 1 que establece que "Es deber del Estado... asegurar el derecho de las personas a participar con igualdad de oportunidades en la vida nacional". Este enfoque, en una primera lectura frecuente del constitucionalismo, fundamenta los derechos indígenas desde la perspectiva de la prohibición de la discriminación (como diferenciación arbitraria). Una segunda lectura, cercana a la primera, pero desde la perspectiva de las acciones afirmativas, es la de justificar la protección de la cultura de los pueblos indígenas como "grupos vulnerables" 29 . Nosotros, sin perjuicio de la validez de los dos primeros enfoques, según el contexto de ejercicio de los derechos de que se trate, sostendremos que los pueblos indígenas pueden fundamentar el DFICPI a la luz del principio de igualdad constitucional comprendido como el derecho a ejercer y asumir la diferencia como una dimensión de la dignidad humana en cuanto tal -en su dimensión individual y en la social o colectiva-. Tenemos claro que la dimensión colectiva cultural de los derechos indígenas, se debate frente a una concepción igualitaria liberal ${ }^{30}$. No obstante, primero, teóricamente, siguiendo a Díaz Polanco, entendemos que ambas dimensiones convergen en la dignidad humana, lo que nos lleva a buscar puentes entre ellas ${ }^{31}$. Y, segundo, más allá de debates teóricos sobre el DFICPI ${ }^{32}$, seguimos a la Corte I.D.H que reconoció expresamente la naturaleza colectiva y de derecho fundamental al derecho a la identidad cultural cuando su ejercicio corresponde a los pueblos indígenas ${ }^{33}$.

En el sentido indicado, el principio de igualdad no inhibiría la existencia de estatutos o normativas especiales, en la perspectiva afirmativa que ha planteado el Tribunal Constitucional

\footnotetext{
${ }^{26}$ Corte Suprema Rol N²840-2008, de 25 de noviembre de 2009, cons. séptimo; Corte Suprema, Rol № 10.090-2011, de 22 de marzo de 2012, cons. Quinto. En la misma línea los fallos: Tribunal Constitucional, Rol № 2387-2012, de 23 de enero de 2013, cons. décimo segundo; Tribunal Constitucional, Rol N²552-2013, de 24 de diciembre de 2015, cons. séptimo y octavo. También, véase ESPINOZA (2017). ${ }^{27}$ BIDART (2002).

${ }^{28}$ Corte de Apelaciones de Temuco, Rol N 1773-2008, de 16 de septiembre de 2009, cons. segundo, tercero, décimo quinto.

${ }^{29}$ BELTRÂO et al. (2014), p. 11.

${ }^{30}$ Puede revisarse, a lo menos, desde dos perspectivas teóricas. Desde un enfoque histórico, como costumbre jurídica, como lo plantea ESPINOZA (2017), pp. 413-419. Asimismo, puede revisarse desde una perspectiva filosófica, en relación con los alcances del principio de igualdad liberal y su capacidad de justificar el reconocimiento del derecho a la identidad cultural. Al efecto, algunos autores europeos limitan este reconocimiento, HONNETH (2006), p. 133; BENHABIB (2006), p. 10. Mientras desde una perspectiva latinoamericana se defiende el sentido democrático del reconocimiento indígena y su identidad cultural, FAUNDES (2017b).

${ }^{31}$ DÍAZ (2000), p. 1010.

${ }^{32}$ Sobre los alcances y debates en torno a la perspectiva individual y la colectiva del derecho a la identidad cultural véanse: RUIZ (2006), pp. 43-69 y DEL REAL (2014).

${ }^{33}$ Corte IDH, Pueblo Indígena Sarayaku Vs. Ecuador, de 27 de junio de 2012, cons. 213 y 217. En el mismo sentido la Corte Constitucional de Colombia, Sentencia T-778/05.
} 
chileno, frente a sectores o grupos vulnerados históricamente de la sociedad ${ }^{34}$. Pero, además, el principio de igualdad comprendería un conjunto de nuevas categorías normativas en relación al DFICPI, entre otras, en materia de propiedad, justicia y participación. Por ello, emerge el desafío de examinar la legislación nacional y las respectivas regulaciones sectoriales frente los nuevos estándares que se hacen exigibles con los derechos de los pueblos indígenas internacionalmente reconocidos. Así, el principio de igualdad, en relación al DFICPI, debiera entenderse en un sentido amplio, evolutivo, como el derecho humano radicado en la dignidad fundamental de toda persona a desenvolverse y desarrollar su vida conforme todos los aspectos de su identidad personal, lo que, por cierto, comprende su identidad y marco cultural, incluso en un sentido colectivo como miembro de un grupo específico que comparte valores culturales, espirituales, religiosos y normas sociales, entre otros (una cosmovisión y una cultura de origen ancestral en el caso de los pueblos indígenas) ${ }^{35}$.

Conjuntamente, el derecho a la identidad cultural se ve reforzado por los siguientes derechos fundamentales contemplados en el artículo 19 de la Constitución:

i) El derecho de toda persona al "respeto y protección a la vida privada y a la honra de la persona y su familia", del artículo 19 № 4, que se ha entendido inclusivo del derecho fundamental a la identidad personal y a "la imagen", implícito en la disposición referida ${ }^{36}$. Esta cuestión, precisamente, fue resuelta por la Corte Suprema, enlazando el derecho a la identidad, desde la perspectiva de la imagen ${ }^{37}$, con los derechos culturales de un demandante indígena, Machi ${ }^{38}$ del Pueblo Mapuche ${ }^{39}$.

ii) El derecho a la "libertad de conciencia y de religión", del artículo $19 \mathrm{~N}^{\circ} 6$. En este sentido, la Corte Suprema se pronunció en el Caso del Cerro Topater, expresando que se perturbó "el derecho legítimo que tienen las recurrentes, tanto al libre ejercicio y desarrollo de sus creencias religiosas y ritos sagrados [conforme el № $6^{\circ}$ del artículo 19] de modo que, de tolerar que se los pase a llevar, se los diferenciaría, arbitrariamente... contrariándose de esa forma, además, la garantía de igualdad y no discriminación que sienta el numeral $2^{\circ}$ del propio artículo $19^{\prime \prime 4}$.

iii) Procesalmente, el derecho a la igual protección de la ley, conforme el artículo 19 № 3, que comprende el derecho de toda persona a la defensa jurídica en la forma que la ley señale. En particular, el derecho a que la persecución penal y las respectivas herramientas de defensa, consideren el contexto cultural en que se encuadra la conducta que es objeto de reproche penal, ante lo cual se ha sostenido existiría un derecho fundamental emergente, de naturaleza procesal e innominado, al peritaje antropológico ${ }^{41}$. Todo ello, en armonía con el "derecho a las garantías judiciales" y el derecho a la "protección judicial" garantizados por la CADH" ${ }^{42}$. En especial, con el

\footnotetext{
${ }^{34}$ Tribunal Constitucional, Rol N²552-2013, de 24 de diciembre de 2015, cons. sexto.

Sobre alcances del principio de igualdad en el Tribunal Constitucional, DÍAZ DE VALDÉS (2015).

${ }^{35}$ En este sentido el Juez Abreu Burelli planteó que los artículos 24 (Igualdad ante la Ley) y 1.1 (Obligación de Respetar los Derecho) de la $\mathrm{CADH}$ son dos ejes transversales del conjunto de derechos que comprende el DFICPI de los pueblos indígenas en el sentido que "son libres e iguales a todas las personas en dignidad y derechos y deberán gozar plenamente de los derechos humanos y las liberta des fundamentales, sin obstáculos y discriminación de ninguna índole". Corte IDH, Comunidad Indígena Yakye Axa Vs. Paraguay, de 17 de junio de 2005, cons. 34, voto parcialmente disidente.

${ }^{36}$ Tribunal Constitucional, Rol N 1340-2009, de 29 de septiembre de 2009, cons. vigésimo; Tribunal Constitucional, Rol N¹537-2009, de 1 de septiembre de 2011; Tribunal Constitucional, Rol N¹563-2009, de 30 de agosto de 2011; y Tribunal Constitucional, Rol N¹656-2010, de 1 de septiembre de 2011.

${ }^{37}$ Para NOGUEIRA (2007), p. 260, el derecho a la imagen se trata de un derecho fundamental implícito y autónomo.

${ }^{38}$ Autoridad tradicional Mapuche vinculada al área de la religión y la salud.

${ }^{39}$ Corte de Apelaciones de Valdivia, Rol N 651-2012, de 7 de diciembre de 2012, cons. séptimo; Corte Suprema, Rol N $481-2013$, de 25 de septiembre de 2013, cons. quinto.

${ }^{40}$ Corte Suprema, Rol N³010-2013, de 26 de septiembre de 2013, cons. 11.

${ }^{41}$ RUIZ (2015), p. 132.

${ }^{42} \mathrm{CADH}$, arts. 8 y 25; Convenio 169, art. 12; DNUDPI art. 13.
} 
derecho del imputado a obtener la comparecencia de peritos e interrogarlos, como parte del derecho a presentar prueba de descargo, que en su conjunto conforman el bloque de garantías del derecho a defensa y del derecho a un justo proceso ${ }^{43}$. Luego, el derecho indicado a obtener la comparecencia de peritos, también de autoridades tradicionales indígenas (como un o una machi o un longko en el caso Mapuche $)^{44} u$ otros miembros de la comunidad indígena, que den cuenta del contexto cultural del caso conocido por el juez, habilita concretamente la posibilidad efectiva de defensa cultural que - como dijimos- es una expresión procesal del DFICPI.

iv) Por último, el DFICPI se vincula con dos garantías constitucionales que en materia de derechos de los pueblos indígenas se han comprendido de manera conexa: el derecho a vivir en un medio ambiente libre de contaminación del artículo $19 \mathrm{~N}^{\circ} 8$ y la protección del dominio del artículo $19 \mathrm{~N}^{\circ} 24$ (amparando la propiedad indígena). Ambos confluyen en la protección de los derechos territoriales indígenas, en tanto hábitat y territorios indígenas ${ }^{45}$. A modo de ejemplo, el primer fallo dictado por un Tribunal Superior de Justicia en Chile aplicando el Convenio $N^{\circ} 169$ de la OIT, confirmado por la Excma. Corte Suprema, se pronunció sobre el alcance constitucional de los conceptos de "territorio" y su directa relación con el "hábitat", "bajo interdependencia con los derechos culturales", la protección del medio ambiente y los derechos de los pueblos indígenas en general, conforme el Convenio 169. Se señaló que se había vulnerado la garantía constitucional del derecho a vivir en un medio ambiente libre de contaminación del artículo 19 № 8 de la Constitución, adscribiendo expresamente a una interpretación amplia del concepto de "medio ambiente" que incorporó los elementos culturales propios de la cosmovisión indígena mapuche ${ }^{46}$.

\section{EI DFICPI en el Derecho Internacional de los Derechos Humanos}

Se ha entendido por identidad cultural como el conjunto de referentes culturales con los que "una persona o un grupo se autodefine, se manifiesta y desea ser reconocido" ${ }^{77}$. Comprende dos conceptos articulados, identidad y cultura. Entonces, podemos desprender que el derecho a la identidad cultural contempla, al mismo tiempo, dos derechos: el derecho a la identidad y el derecho a la cultura. El derecho a la identidad refiere al resguardo del sentido de pertenencia que un individuo tiene respecto de un determinado grupo o cultura ${ }^{48}$. $\mathrm{Y}$, por otra, este derecho fundamental apunta a la protección de la cultura a la que pertenece el sujeto.

Asimismo, este derecho fundamental puede leerse desde dos puntos de vista, como derecho individual y como derecho colectivo. En tanto derecho individual protege al individuo y su identidad en la comunidad ${ }^{49}$; como derecho colectivo resguarda a la comunidad, como sujeto de derecho ${ }^{50}$. La segunda perspectiva es la que suscita mayor debate ${ }^{51}$. No obstante, también, es la que

\footnotetext{
${ }^{43}$ Art. 8, letra f) $\mathrm{CADH}$ y art. 14 PDCP.

${ }^{44}$ Se ha aceptado el testimonio de machi, como autoridad tradicional para explicar asuntos de la cosmovisión mapuche (enfermedad mapuche o mapu kutran), bajo la forma de testigo experto. TOP de Temuco, RIT No 107-2013.

${ }^{45}$ Corte Suprema, Rol N 2840-2008, de 25 de noviembre de 2009; Corte Suprema, Rol No 14.003-13, de 15 de mayo de 2014; Corte Suprema, Rol N 3010-2013, de 26 de septiembre de 2013; Corte Suprema, Rol º 6628-2015, de 4 de mayo de 2016.

${ }^{46}$ Corte de Apelaciones de Temuco, Rol N 1773-2008, de 16 de septiembre de 2009, confirmada Corte Suprema, Rol N 7287- 2009, de 30 de noviembre de 2009.

${ }^{47}$ RUIZ (2006), p. 44.

${ }^{48}$ GRIMSON (2010), pp. 63-79.

${ }^{49}$ DEL REAL (2014).

${ }^{50}$ Corte Constitucional de Colombia, Sentencia T-778/05; RUIZ (2006), pp. 43-69; DEL CARPIO (2014), pp. 48-49.

${ }^{51}$ El derecho a la cultura ha sido objeto de importantes debates que, por exceder este trabajo, solo referiremos brevemente. Primero, en una mirada europea, se ha refutado la enunciada dimensión colectiva del derecho a la identidad cultural, DEL REAL (2014). También, el derecho a la identidad cultural, supeditados a los derechos humanos individuales, ELÓSEGUí (2012), pp. 54-56. O bien, se cuestiona la
} 
se alza como más relevante para el aseguramiento de los derechos de los pueblos indígenas - como veremos-.

El derecho a la identidad cultural, ha sido fruto de la transformación del Derecho Internacional de los derechos humanos y de la profundización de los estándares de protección de las minorías culturales (principalmente étnicas y religiosas). El caso más normativamente más avanzado es el de los pueblos indígenas, ya que la Corte I.D.H reconoció a estos pueblos como titulares del derecho fundamental a la identidad cultural y admitió expresamente la naturaleza colectiva de este derecho cuando su ejercicio se realiza por los pueblos indígenas ${ }^{52}$.

Sin extendernos en este trabajo, es necesario explicar brevemente que el carácter de derecho fundamental reconocido por la Corte IDH al derecho a la identidad cultural tendría el efecto de incorporarlo al bloque constitucional de derechos fundamentales normado constitucionalmente ${ }^{53}$. Entonces, pasaría a constituir una norma imperativa para el Estado constituyendo un límite para el ejercicio de la soberanía por parte de este ${ }^{54}$. Por su parte, el DFICPI se recoge de la interpretación auténtica y vinculante formulada por la Corte IDH siguiendo la CADH, dado que su tenor literal no considera este derecho expresamente. Por ello, también podemos considerar al DFICPI como un derecho implícito en la CADH, cuyo reconocimiento es fruto de la hermenéutica evolutiva de los derechos humanos.

Ahora bien, visto el DFICPI desde la perspectiva de los restantes instrumentos internacionales de derechos humanos, en un nivel general, se ha ido dando desarrollo progresivo al DFICPI siguiendo la Declaración Universal de Derechos Humanos que dispone que "Toda persona, como miembro de la sociedad, tiene derecho a obtener 'la satisfacción de los derechos económicos, sociales y culturales, indispensables a su dignidad y al libre desarrollo de su personalidad'" (art. 22) y que toda persona "tiene derecho de participar libremente en la vida cultural de la comunidad" (art. 27.1). Asimismo, el PIDESC, en su artículo 1 señala que "Todos los pueblos tienen el derecho de libre determinación. En virtud de este derecho establecen libremente su condición política y proveen asimismo a su desarrollo económico, social y cultural". Ello se articula con el artículo 27 del PIDCP que dispone que

En los Estados en que existan minorías étnicas, religiosas o lingüísticas, no se negará a las personas que pertenezcan a dichas minorías el derecho que les corresponde, en común con los demás miembros de su grupo, a disfrutar de su propia cultura, a profesar y practicar su propia religión y a emplear su propio idioma.

Asimismo, la Convención para la salvaguardia del patrimonio cultural inmaterial (Paris, 2003) protege el patrimonio cultural inmaterial (art. 1.a) y dispone la obligación de respetar el

\footnotetext{
justificación en las democracias occidentales la demanda por el derecho a la cultura, porque este reconocimiento puede ser detonante de conflictividad social HONNETH (2006), pp. 131-132. No obstante, esta última afirmación también ha sido refutada. En síntesis, se argumenta en contrario que, si queremos promover un sentido amplio e inclusivo de la igualdad democrática, deben tener cabida los diversos grupos, considerando sus condiciones basales de sobrevivencia, como son las culturales en el caso de los pueblos ind ígenas. Luego, suscitados conflictos culturales, el desafío democrático radica en la construcción institucional de mecanismos para enfrentar esos conflictos y no en la supresión a priori de sujetos colectivos o de la dimensión cultural de los derechos de tales grupos, FAUNDES (2017a); FAUNDES (2017b); y FAUNDES (2015c).

${ }^{52}$ Corte IDH, Pueblo Indígena Sarayaku Vs. Ecuador, de 27 de junio de 2012, cons. 213 y 217. En el mismo sentido la Corte Constitucional de Colombia, Sentencia T-778/05.

${ }^{53}$ NOGUEIRA (1997).

${ }^{54}$ Corte de Apelaciones de Rancagua, Rol № 103-2011, de 14 de enero de 2013; NOGUEIRA (1997); ALDUNATE (2010).
} 
"patrimonio cultural inmaterial de las comunidades, grupos e individuos..." (1.b), asegurando de esta forma el DFICPI ${ }^{55}$.

Dentro de los instrumentos específicos referentes a los pueblos indígenas, sí se asegura el DFICPI de manera explícita. Encontramos la DNUDPI, el Convenio N 169 y la DADPI (2016). La DNUDPI asegura el derecho a la identidad como un derecho humano de naturaleza colectiva, expresando que la identidad se forja en el sentido de pertenencia que se tiene a un grupo humano, del que como individuo se siente parte y que se sustenta en el comportamiento de esa colectividad. La DNUDPI ampara el derecho a la identidad cultural cuando dispone que "Los pueblos y los individuos indígenas tienen derecho a pertenecer a una comunidad o nación indígena, de conformidad con las tradiciones y costumbres de la comunidad o nación de que se trate" (art. 9). También, cuando señala que

Los pueblos indígenas tienen derecho a practicar y revitalizar sus tradiciones y costumbres culturales. Ello incluye el derecho a mantener, proteger y desarrollar las manifestaciones pasadas, presentes y futuras de sus culturas, como lugares arqueológicos e históricos, objetos, diseños, ceremonias, tecnologías, artes visuales e interpretativas y literaturas. (art. 11.1)

al amparar los bienes culturales, intelectuales, religiosos y espirituales (art. 11.2) y el derecho "a determinar su propia identidad o pertenencia conforme a sus costumbres y tradiciones" (art. 33.1).

Por su parte, el Convenio 169 fundamenta y protege el derecho a la identidad cultural al establecer la obligación de respeto y garantía de "su integridad" (art. 2.1). Considerando la promoción de la plena "efectividad de los derechos sociales, económicos y culturales de esos pueblos, respetando su identidad social y cultural, sus costumbres y tradiciones, y sus instituciones" (art. 2.2.b) En armonía con el DFICPI, el Convenio 169 también asegura el derecho de los pueblos indígenas a

decidir sus propias prioridades en lo que atañe al proceso de desarrollo, en la medida en que éste afecte a sus vidas, creencias, instituciones y bienestar espiritual y a las tierras que ocupan o utilizan de alguna manera, y de controlar, en la medida de lo posible, su propio desarrollo económico, social y cultural. (art. 7.1).

Conforme con ello, los Gobiernos, en la aplicación del Convenio 169:

deberán respetar la importancia especial que para las culturas y valores espirituales de los pueblos interesados reviste su relación con las tierras o territorios, o con ambos, según los casos, que ocupan o utilizan de alguna otra manera, y en particular, los aspectos colectivos de esa relación (art. 13.1).

En el plano regional americano, la CADH fundamenta el DFICPI a partir de sus artículos 1.1, 4, 11, 21, 24, 29.b (lo revisaremos conforme la jurisprudencia de la Corte IDH). Por su parte, la Organización de Estados Americanos (OEA) con fecha 14 de junio de 2016 aprobó la "Declaración Americana sobre los derechos de los pueblos indígenas" (DADPI), que considera el derecho a la identidad cultural como un valor transversal. En la Sección tercera (arts. XIII a XIX) aborda en particular y extensamente el derecho a la identidad cultural. Trata el DFICPI como categoría en sí (art. XIII), conforme el cual los pueblos indígenas, colectivamente, "tienen derecho a su propia

\footnotetext{
${ }^{55}$ Por su parte el artículo 2 señala que el "patrimonio cultural inmaterial" comprende, entre otros: las (a) "tradiciones y expresiones orales, incluido el idioma", (c) los "usos sociales, rituales y actos festivos; los (d) "conocimientos y usos relacionados con la naturaleza y el universo; y las (e) "técnicas artesanales tradicionales".
} 
identidad e integridad cultural y a su patrimonio cultural, tangible e intangible"; y en relación con un conjunto de derechos específicos, tales como: conocimiento tradicional (art. 13.3), lenguaje, comunicación (art. 14), educación y salud indígena (art. 15 y 18), espiritualidad art. 16), familia indígena (art. 17) y protección del medio ambiente sano (art. 19).

\section{EI DFICPI como categoría emergente a partir de la jurisprudencia evolutiva interamericana}

El reconocimiento del DFICPI por la Corte IDH solo se ha logrado a lo largo de un proceso hermenéutico progresivo de cuatro décadas, para llegar a configurarse como el núcleo articulador de lo que se ha denominado un corpus juris de derechos humanos de los pueblos indígenas ${ }^{56}$. En este sentido, la Corte Interamericana ha reconocido el DFICPI y ha ido estableciendo progresivamente los alcances y estándares de este derecho.

Presentamos a continuación una revisión jurisprudencial considerando aspectos relevantes de los fallos específicos de la Corte IDH en los que se dota de contenido al DFICPI (considerando la importante influencia de algunos de sus jueces mediante sus votos particulares) y se enlaza, de forma inalienable, con el derecho a las tierras, territorios y sus recursos naturales, como sostenedores de la propia sobrevivencia de los pueblos indígenas, comprensiva de su identidad cultural ${ }^{57}$, el reconocimiento de las prácticas indígenas, sus costumbres y derecho consuetudinario. Todo ello será la base concreta que le permitirá ir dotando de contenido progresivamente al DFICPI. En el sentido indicado, el Juez Cançado Trindade expresó muy ilustrativamente que:

[...] la importancia de las culturas, - como vínculo entre cada ser humano y la comunidad en que vive (el mundo exterior) - [...] En medios sociales fuertemente impregnados de una visión comunitaria... prevalece un sentimiento de armonía entre los vivos y los muertos, entre el ambiente natural y los espíritus que lo animan. Las manifestaciones culturales deben encontrar expresión en el mundo del Derecho [se trata] del reconocimiento de la relevancia de la identidad y diversidad culturales para la efectividad de las normas jurídicas ${ }^{58}$.

En el año 2001 se marca un punto de inflexión jurisprudencial con la sentencia de la Corte IDH sobre el Caso de la "Comunidad Magna (Sumo) AwasTigni" (2001). En esta decisión ya se dan por establecidos los aspectos basales de los derechos de los pueblos indígenas que reconoce la Corte como comprendidos por la CADH. En especial, en relación al artículo 21 de la CADH, se pronuncia sobre la autonomía conceptual y normativa de la propiedad indígena respecto de la concepción de la propiedad registral predominante y la necesidad del amparo de la propiedad indígena ancestral dada su íntima relación con la sobrevivencia misma de estos pueblos. Dijo la Corte que:

[...] entre los indígenas existe una tradición comunitaria sobre una forma comunal de la propiedad colectiva de la tierra, en el sentido de que la pertenencia de ésta no se centra en un individuo sino en el grupo y su comunidad. Los indígenas por el hecho de su propia existencia tienen derecho a vivir libremente en sus propios territorios; la estrecha relación que los indígenas mantienen con la tierra debe de ser reconocida y comprendida como la base fundamental de sus culturas, su vida espiritual, su integridad y su supervivencia económica. Para las comunidades indígenas la relación con la tierra

\footnotetext{
${ }^{56}$ La idea de un corpus juris de derechos humanos de los pueblos indígenas se desprende de la propia jurisprudencia de la Corte IDH; AYLWIN et al. (2013), p. 550.

${ }^{57}$ Corte IDH, Mary y Carrie Dann con Estados Unidos (2002), cons. 128.

${ }^{58}$ Corte IDH (2000), Bámaca Velásquez Vs. Guatemala, de 25 de noviembre de 2000, cons. 24, voto razonado, Juez Cançado Trindade.
} 
no es meramente una cuestión de posesión y producción sino un elemento material y espiritual del que deben gozar plenamente, inclusive para preservar su legado cultural y transmitirlo a las generaciones futuras ${ }^{59}$.

Más tarde, en 2005, el Juez CançadoTrindade señaló que:

el desarraigo afecta, en última instancia, al derecho de una identidad cultural que compone el contenido sustantivo o material del derecho a la vida misma lato sensu... incluyendo el derecho a una identidad cultural, que se manifiesta en sus reconocidos lazos de solidaridad con los muertos ${ }^{60}$.

Explica que la Corte reconoce los daños inmateriales en estrecha relación con el derecho a la identidad cultural de las comunidades indígenas, valorando, por sobre la dimensión subjetiva individual, el daño espiritual cultural colectivo comunitario y la normatividad de las tradiciones territorializadas.

Con el caso de la Comunidad Moiwana Vs. Suriname (2005) se profundiza en la conexión normativa existente entre el DFICPI, la libertad de conciencia y religiosa (que ya se venía reconociendo de manera emergente en los casos Bámaca Velásquez ${ }^{61}$ y de la Masacre Plan de Sánchez $^{62}$ fallados entre 2000 y 2004). En este caso se reafirmará la dimensión colectiva de la identidad cultural, en especial a partir del reconocimiento de un daño de carácter inmaterial "daño espiritual" - que afecta una subjetividad compleja (de los vivos con sus muertos) de "proyección intergeneracional" como forma especial y "agravada de daño moral" que por su propia naturaleza es imposible de indemnizar, pero que sí contiene innovadas modalidades de reparación colectiva, precisamente, respecto de dicho daño espiritual de naturaleza cultural. ${ }^{63}$

En el caso de la Caso Comunidad indígena Yakye Axa Vs. Paraguay (2005) expresó la Corte IDH que, para garantizar efectivamente los derechos a las comunidades indígenas, los Estados deben considerar las características propias que diferencian a los miembros de los pueblos indígenas respecto de la población en general, las que conforman su identidad cultural. Asimismo, especificó que la Corte tomará en cuenta, "la significación especial de la propiedad comunal de las tierras ancestrales para los pueblos indígenas, inclusive para preservar su identidad cultural y trasmitirla a las generaciones futuras"64. En este sentido declaró que "La cultura de los miembros de las comunidades indígenas corresponde a una forma de vida particular de ser, ver y actuar en el mundo" que se conforma "a partir de su estrecha relación con sus territorios tradicionales y los recursos que allí se encuentran... porque constituyen un elemento integrante de su cosmovisión, religiosidad y, por ende, de su identidad cultural" 65 . Incluso, dejó planteado que puede resultar necesaria una restricción que al derecho a la propiedad privada de particulares "para lograr el objetivo colectivo de preservar las identidades culturales en una sociedad democrática y pluralista en el sentido de la Convención Americana"66.

Continuando con la línea jurisprudencial, en el año 2006, la Corte IDH observó que dada "la significación especial" que tiene la tierra para los pueblos indígenas, "toda denegación al goce o

\footnotetext{
${ }^{59}$ Corte IDH, Comunidad Mayagna (Sumo) Awas Tingni Vs. Nicaragua, de 31 de agosto de 2001, cons. 149.

${ }^{60}$ Corte IDH, Caso Comunidad Indígena Moiwana Vs. Surinam, de 15 junio 2005, cons. 92, voto razonado, Juez Cançado Trindade.

${ }^{61}$ Corte IDH, Sentencia de 25 de noviembre de 2004, Caso Bámaca Velásquez Vs. Guatemala.

${ }^{62}$ Corte IDH, Sentencia de 29 de abril de 2004, Caso Masacre Plan de Sánchez Vs. Guatemala.

${ }^{63}$ Corte IDH, Sentencia de 15 de junio de 2005. Caso Comunidad Indígena Moiwana Vs. Surinam, cons. 78, voto razonado, Juez Cançado Trindade.

${ }^{64}$ Corte IDH, Caso Comunidad Indígena Yakye Axa Vs. Paraguay, de 17 de junio de 2005, cons. 51 y 24.

${ }^{65}$ Corte IDH, Caso Comunidad Indígena Yakye Axa Vs. Paraguay, de 17 de junio de 2005, cons. 135.

${ }^{66}$ Corte IDH, Caso Comunidad Indígena Yakye Axa Vs. Paraguay, de 17 de junio de 2005, cons. 148.b).
} 
ejercicio de los derechos territoriales" acarrea el menoscabo de valores relevantes y el peligro consecuente "de perder o sufrir daños irreparables en su vida e identidad y en el patrimonio cultural por transmitirse a las futuras generaciones" 67 .

Entrando en el desarrollo de un conjunto de estándares para el DFICPI, el Juez Cançado Trindade abordó el entendimiento normativo de este derecho en relación con el derecho a la vida. Para él, existe un problema de dos dimensiones, dado, uno, por "la amplia dimensión del derecho fundamental a la vida" y, dos, por "el derecho a la identidad cultural". En este sentido, explica la importancia "de la identidad cultural, como componente o agregado del propio derecho fundamental a la vida" y destaca la relevancia de la recuperación de sus tierras ancestrales "para la protección y preservación de 'su propia identidad cultural y, en última instancia, su derecho fundamental a la vida lato sensu" ${ }^{\prime \prime 68}$. Señala que el derecho a la vida posee una "vinculación estrecha e ineludible con la identidad cultural", porque la identidad cultural "se forma con el pasar del tiempo, con la trayectoria histórica de la vida en comunidad. La identidad cultural es un componente o agregado del derecho fundamental a la vida en su amplia dimensión". Si se les priva de sus tierras "se afecta seriamente su identidad cultural y, en última instancia, su propio derecho a la vida lato sensu, o sea, el derecho a la vida de cada uno y de todos los miembros de cada comunidad". Frente a ello - dice- el Estado "no puede eximirse del deber de debida diligencia para salvaguardar el derecho de vivir"69. En este sentido, entendemos se impone al Estado un deber de impulsar medidas y actos efectivos para salvaguardar el DFICPI, lo que integra inalienablemente la protección de sus territorios y recursos, en una comprensión amplia del derecho a la vida de los pueblos indígenas, sus comunidades e integrantes.

Por su parte, el juez A. Abreu Burelli, en su voto parcialmente disidente del Caso de la Comunidad Indígena Sawhoyamaxa Vs. Paraguay (2006), enunció los siguientes derechos en particular que entiende amparados en la CADH en relación con el DFICPI: a) Derecho a la Integridad Personal (art. $5 \mathrm{CADH}$ y art. 10 del Protocolo de San Salvador sobre Derecho a la Salud) que comprende el derecho a utilizar "sus propias medicinas y prácticas de salud tradicionales y acceso a la atención de salud estatal en igualdad al resto de la población"; Protección de la Honra y Dignidad (art.11 CADH)

comprende el derecho a no sufrir injerencias arbitrarias o abusivas en su vida privada, familiar y comunal, lo que implica la preservación de su cultura y el respeto a la integridad de los valores, prácticas e instituciones de esos pueblos

c) Libertad de Conciencia y Religión (art. $12 \mathrm{CADH}$ ) como derecho "a preservar, expresar, divulgar, desarrollar, enseñar y cambiar sus prácticas, ceremonias, tradiciones y costumbres espirituales"; d) Libertad de Pensamiento y Expresión (art. 13 CADH), entre otras cuestiones, comprende el derecho a manifestar pública y privadamente su propia cultura, a preservar su propio lenguaje y a ser informados sobre todos los aspectos que afecten su vida espiritual, social y cultural; e) Derecho de Reunión, Libertad de Asociación y Derechos Políticos. (arts. 15, 16, 23 CADH) comprende el derecho "a reunirse y formar asociaciones de conformidad con su propia cultura, valores y derecho consuetudinario"; asegura los Derechos Políticos, permitiendo "organizarse de acuerdo a sus propias formas de organización tradicional, elegir a sus representantes de acuerdo a

\footnotetext{
${ }^{67}$ Corte IDH, Caso de la Comunidad Indígena Sawhoyamaxa Vs. Paraguay, de 29 de marzo de 2006. cons. 222.

${ }^{68}$ Corte IDH, Caso de la Comunidad Indígena Sawhoyamaxa Vs. Paraguay, de 29 de marzo de 2006, cons. I 2 a 7, voto razonado, Juez Cançado Trindade.

${ }^{69}$ Corte IDH, Caso de la Comunidad Indígena Sawhoyamaxa Vs. Paraguay, de 29 de marzo de 2006, cons. VI 28, 34, 35, voto razonado, Juez Cançado Trindade.
} 
sus propias formas de elección y promover su desarrollo de acuerdo con sus aspiraciones y necesidades"; f) Derechos Políticos (art. $23 \mathrm{CADH}$ ), en cuanto el derecho a "participar libremente en todos los niveles de adopción de decisiones en instituciones públicas responsables de políticas y programas que les conciernan"; g) Protección de la Familia. (art. 17 CADH), como derecho a "conservar sus propias formas de organización familiar y de filiación"; Derecho al Nombre. (art. 18 $\mathrm{CADH})$ que comprende el derecho "de atribuir nombres a sus comunidades, lugares y personas, en su propio idioma, y mantenerlos"; Derecho a la Propiedad Privada (art. 21 CADH), en cuanto al derecho "al uso y goce de sus bienes, tanto materiales como inmateriales"

En los fallos posteriores, los esfuerzos de la Corte Interamericana van a reforzar los alcances estructurantes del DPICPI para la consolidación de un corpus juris de derechos humanos de los pueblos indígenas y la primacía de su sobrevivencia como bien jurídico amparado en la CADH. En 2007 la Corte IDH sostuvo que los pueblos indígenas "mantienen una fuerte relación espiritual con el territorio", que son titulares de los derechos a los recursos naturales que han usado tradicionalmente dentro ellos y que la tierra "es una fuente necesaria para la continuidad de la vida y de la identidad cultural de los miembros del pueblo Saramaka [...] sin ellos, la supervivencia económica, social y cultural de dichos pueblos está en riesgo"71. Continúa luego en el fallo del Caso de la Comunidad Indígena Xákmok Kásek Vs. Paraguay (2010), en que la Corte agregó que

la cultura de los miembros de las comunidades indígenas corresponde a una forma de vida particular de ser, ver y actuar en el mundo, constituido a partir de su estrecha relación con sus tierras tradicionales y recursos naturales, no sólo por ser éstos su principal medio de subsistencia, sino además porque constituyen un elemento integrante de su cosmovisión, religiosidad y, por ende, de su identidad cultural72.

En los casos más recientes de "Sarayaku Vs. Ecuador" (2012) y "Xucuro Vs. Brasil" (2018) la Corte IDH consolida su jurisprudencia en relación al reconocimiento del derecho a la identidad cultural como un derecho fundamental amparado por la CADH. Señala la sentencia del caso Sarayaku:

[...] el derecho a la identidad cultural es un derecho fundamental y de naturaleza colectiva de las comunidades indígenas, que debe ser respetado en una sociedad multicultural, pluralista y democrática" [y que es] "vía de interpretación transversal para concebir, respetar y garantizar el goce y ejercicio de los derechos humanos de los pueblos y comunidades indígenas protegidos por la Convención y por los ordenamientos jurídicos internos ${ }^{73}$.

Se establece el DFICPI como fundamento común y marco de interpretación de los demás derechos de los pueblos indígenas asegurados por la $\mathrm{CADH}$, en el sentido de la amplia comprensión y alcance del DFICPI. Asimismo, la Corte, con sus fallos de 2012 y 2018 identifica las acciones que implican la violación de del DFICPI de los pueblos indígenas y establece sanciones concretas contra los estados por su vulneración, considerada expresamente como un incumplimiento de la CADH. Dijo la Corte en el caso "Xucuro Vs. Brasil" (2018) que conforme el artículo 21 de la Convención es necesario resguardar su conexión con sus territorios y los recursos naturales que han usado

\footnotetext{
${ }^{70}$ Corte IDH, Caso Comunidad Indígena Yakye Axa Vs. Paraguay, de 6 de febrero de 2006. Voto parcialmente disidente Juez Alirio Abreu, cons. 20 a 34 .

${ }^{71}$ Corte IDH, Caso del Pueblo Saramaka Vs. Surinam, de 28 de noviembre de 2007, cons. 82 y 121.

72 Corte IDH, Comunidad indígena Xákmok Kásek Vs. Paraguay, de 24 de agosto de 2010, cons. 174.

${ }^{73}$ Corte IDH, Pueblo Indígena Sarayaku Vs. Ecuador, de 27 de junio de 2012, cons. 213 y 217.
} 
tradicionalmente porque "son necesarios para su supervivencia física y cultural". Asimismo, destacó la obligación de actuación positiva (diligente) por parte del Estado en favor de los miembros de la Comunidad Sukuro, señalando que debe garantizarles, mediante medidas efectivas, el derecho "a continuar viviendo su modo de vida tradicional, conforme a su identidad cultural, estructura social, sistema económico, costumbres, creencias y tradiciones distintivas" 74 .

\section{Perspectivas de impacto del DFICPI para el ordenamiento jurídico chileno}

El ejercicio del DFICPI nos plantea la necesidad de estudiar los efectos concretos de este derecho sobre el sistema normativo chileno e identificar en qué materias su recepción ha tenido o puede tener mayor impacto ${ }^{75}$. Entonces, nuestro objetivo en este acápite es solo identificar ejemplarmente algunos campos de impacto de mayor relevancia y las brechas que se visibilizan en este, todo, como base para un posterior trabajo sobre los respectivos mecanismos de aseguramiento progresivo del DFICPI. Por ello, a continuación presentamos sucinta y solo ejemplarmente algunas materias en que se aprecia el impacto de la recepción del DFICPI en Chile: en un horizonte reconocimiento constitucional de los pueblos indígenas; en materia penal; de derechos territoriales; y en relación a los recursos naturales, en su vinculación con la participación y la consulta indígena ${ }^{76}$.

Primero, es relevante en relación a la cuestión del reconocimiento constitucional de los pueblos indígenas, porque un eventual proceso de reforma constitucional en la materia debiera incluir en su texto el DFICPI, incorporando las obligaciones de aseguramiento del derecho que hemos revisado, tomando como base el estándar avanzado por la jurisprudencia interamericana.

Segundo, respecto de las cuestiones penales, la recepción progresiva del DFICPI de los pueblos indígenas abre puentes de articulación entre la justicia estatal y las formas de justicia indígena. El presupuesto básico radica en que el examen penal de la conducta objeto de reproche de imputados indígenas "se debe encuadrar dentro del contexto cultural, de los referentes de sentido, propios del contexto histórico, social y cultural en que se sitúa aquella acción o conducta penalmente relevante (para el Estado)"77. Bajo este enfoque, identificamos, a lo menos tres áreas en que el DFICPI tiene incidencia y que requieren seguirse estudiando. i) la validación de las formas autónomas de resolución de conflictos y -en su caso- la sanción de las conductas ilícitas cometidas por los miembros de pueblos indígenas. En este tópico, un hecho considerado delito en la normativa penal del Estado también resulta una acción reprochada en la cultura indígena, aunque en ella puede recibir un tratamiento diferente a la sanción retributiva y de acuerdo al DFICPI se debiese priorizar la forma de reparación, restauración o sanción propia del sistema indígena (art. 9 Convenio 169$)^{78}$. ii) el tratamiento diferenciado en la determinación y cumplimiento de las penas (art. 10 del Convenio169), tanto en la potencial decisión de los jueces de fijar formas de cumplimiento no privativas de libertad, como en el tratamiento culturalmente adecuado en el

\footnotetext{
${ }^{74}$ Corte IDH, Pueblo Indígena Xucuru y otros con Brasil, de 5 de febrero de 2018, cons. 188.

75 Desde la perspectiva de nuestro trabajo, los desafíos de adecuación que plantearemos se radican en el "deber de actuación diligente" que exige la Corte IDH al Estado - según revisamos-, por lo que no se busca aquí debatir sobre autoejecutabilidad del Convenio 169 o sobre su mayor o menor valor vinculante como instrumento internacional. Con todo, a ese respecto, se ha formulado una dura importante crítica, CARMONA (2013), p. 32; NÚÑEZ (2012), p. 234, a la tesis del Tribunal Constitucional de la (no) auto ejecutabilidad del Convenio 169, en tanto este Tribunal no tendría competencia para delimitar los alcances de un tratado internacional, ni para imponer su racio decidendi, en sí, más allá de su juicio de constitucionalidad sobre la disposición sometida a su control.

${ }^{76}$ Un análisis in extenso de la Ley Indígena 19.253 y otros instrumentos nacionales lo realiza ESPINOZA (2017), desde un enfoque de la

"costumbre indígena" que converge con el nuestro.

${ }^{77}$ FAUNDES (2019), p. 73.

78 VILLEGAS Y MELLA (2017), pp. 74-75.
} 
ámbito intrapenitenciario ${ }^{79}$. iii) la llamada "defensa cultural" o cultural defences ${ }^{80}$ y el denominado "delito culturalmente motivado" 81 . Especialmente, este tercer supuesto, debe entenderse en armonía con el artículo 54 de la Ley 19.253 que reconoce en Chile la costumbre indígena como antecedente para la aplicación de una eximente o atenuante de responsabilidad penal ${ }^{82}$. Ahora bien, la cuestión que sostenemos no radica en que la dogmática penal ha usado categorías como el "error de prohibición", el "error de comprensión" y la "inimputabilidad" 83 que suponen una hegemonía cultural y se contraponen con una nueva hermenéutica armónica con el DFICPI ${ }^{84}$, más allá del tenor literal de las fuentes referidas (del Convenio 169 o de la Ley 19.253). Luego, conforme las circunstancias en concreto del caso, cuando una defensa basada en el contexto cultural se funde en el DFICPI, podrá invocar el "ejercicio legítimo de un derecho" y la "atipicidad" 85 como exención de responsabilidad penal. En este campo, el esfuerzo de adecuación normativa radica principalmente en un giro hermenéutico en torno a la comprensión de las categorías penales ${ }^{86}$.

Segundo, el DFICPI incide directamente en la comprensión de los derechos territoriales de los pueblos indígenas y a los recursos naturales que existen en estos. A su vez, esta cuestión, normativamente, tiene dos grandes escenarios. Uno, que corresponde al derecho a las tierras y territorios de uso ancestral, perdidos a lo largo de los diversos procesos de expansión histórica sobre los territorios indígenas, inicialmente por parte de la Corona Española, más tarde desde finales del siglo XIX y durante el siglo XX, por el Estado de Chile. Este derecho es basal y el más visibilizado, porque la existencia indígena misma está asociada a una base material territorial. Así, por ejemplo, el artículo 13 de la Ley Indígena 19.253, en cualquier esfuerzo hermenéutico judicial, debiera privilegiar el sentido precautorio de espacios territoriales culturalmente significativos y descartar interpretaciones conducentes a la desprotección de estas tierras.

La otra faz de estos derechos, corresponde a los recursos naturales existentes en los territorios indígenas (incluidas las aguas de uso ancestral) y a la protección de los espacios de significación cultural, frente a proyectos de inversión que los afectan. En estas materias, los estándares fijados en materia de propiedad indígena por la Corte IDH exigen al Estado replantearse la comprensión romanística registral de la propiedad, que se abre hacia la idea de territorio, bajo un sentido autónomo de la propiedad indígena que es amparada por la CADH (art. 21) ${ }^{87} 88$.

Tercero, destacamos el derecho a la consulta indígena y los presupuestos de afectación directa versus la susceptibilidad de afectación sobre pueblos indígenas, requeridos para su exigibilidad que han recibido muy diversas lecturas desde la legislación interna y doctrina chilena, especialmente la ambiental. En especial, el problema se presenta con los llamados efectos intangibles o aquellos no perceptibles por quienes no son miembros de los pueblos indígenas ${ }^{89}$, cuya determinación corresponde se establezca autónomamente por los propios afectados. En esta materia, el DFICPI implica un cambio de paradigma en Chile en relación a la exigencia jurisprudencial mayoritaria de evidenciar grados de afectación directa y de forma previa a la ocurrencia de un

\footnotetext{
79 DPP $(2015 ; 2017)$.

${ }^{80}$ DE MAGLIE (2012), p. 136.

${ }^{81}$ DE MAGLIE (2012).

${ }^{82}$ AYLWIN (1995), p. 196.

${ }^{83}$ KALINSKY (2000), pp. 245-247.

${ }^{84}$ FAUNDES (2019).

85 KALINSKY (2000), pp. 156-161; DE MAGLIE (2012), pp. 193-237.

${ }^{86}$ En FAUNDES (2019) se hace una revisión más amplia de esta propuesta hermenéutica penal.

${ }^{87}$ Corte IDH, Awas Tigni Vs. Nicaragua, de 31 de agosto de 2001.

88 ROJAS (2014), p. 66; AYLWIN et al. (2012), pp. 547-548; FAUNDES (2015a); ESPINOZA (2017).

${ }^{89}$ ANAYA (2009), p. 23, parr. 62.
} 
proceso de consulta ${ }^{90}$. Mientras, a la luz del DFICPI, el correcto sentido debiera ser el de la susceptibilidad de afectación (como afectación potencial) que activa un proceso de consulta, bajo una perspectiva eminentemente cautelar de la consulta que exige un mínimo estándar probatorio en las etapas preliminares ${ }^{91}$. En este sentido, conforme el DFICPI, si la medida es susceptible de afectar a los pueblos indígenas, deberá gatillarse tal procedimiento de consulta ${ }^{92}$. Incluso, se ha sostenido que el Estado debiera demostrar que no hay afectación ni susceptibilidad de ella ${ }^{93}$.

\section{Conclusiones}

Hemos procurado fundamentar el DFICPI, tanto desde sus fuentes internacionales, como desde una perspectiva autónoma constitucional, haciendo dialogar ambos niveles normativos (internacional y nacional).

Si bien el campo estudiado del DFICPI está cruzado por debates que este trabajo está lejos de agotar, hemos aportado argumentos que nos permiten sostener, conforme una hermenéutica constitucional armónica con el Derecho Internacional de los derechos humanos y en el sentido descrito la jurisprudencia de la Corte IDH, que el DFICPI es un derecho cuyo amparo se puede justificar en la Constitución Política Chilena. En concreto, desde esta perspectiva, la identidad cultural goza de relevancia para el Derecho como bien jurídico que requiere tutela constitucional. Aunque, dicho amparo, exigirá un esfuerzo hermenéutico que tensiona el cómo se venía pensando la Constitución.

Conforme la jurisprudencia de la Corte IDH, el DFICPI es un derecho basal, transversal, cuyo ejercicio efectivo es presupuesto inalienable de los restantes derechos de los pueblos indígenas. Por ejemplo: derechos territoriales, a los recursos naturales y a la consulta; el derecho a la libertad religiosa, de conciencia y de expresión (en sentido colectivo cultural); el de participación política y a las propias formas de organización; a la familia, en sentido comunitario y a la vida misma, en sentido amplio, entendida como derecho a la sobrevivencia de estos pueblos y sus comunidades.

En consecuencia, la vulneración de los derechos enlazados con el DFICPI, como la pérdida de derechos territoriales de estos pueblos, la afectación de sus recursos naturales, hábitat y espacios de significación cultural o la imposición de sanciones penales al margen de su comprensión y contexto cultural, pueden acarrear el menoscabo de valores culturales propios de dichos pueblos y sus miembros, con lo que arriesgan sufrir daños irreparables en su identidad cultural como bien colectivo.

Así, el Estado tiene el desafío de implementar medidas concretas y efectivas de adecuación normativa que respeten y aseguren el DFICPI. A su vez, será necesario desarrollar mecanismos para articular y resolver los conflictos y tensiones normativas que puedan generarse con esta tarea.

\footnotetext{
${ }^{90}$ Entre otros, Corte Suprema, Rol № 9526-2012, de 17 de enero de 2013.

${ }^{91}$ Casos similares se presentan con las concesiones de exploración geotérmica y con las centrales de generación hidroeléctrica de menos de $3 \mathrm{MW}$, porque ambas actividades no están sometidas al Sistema de Evaluación Ambiental y se ha supuesto para ellas un bajo impacto ambiental que excluiría la consulta, pero a la luz del DFICPI de los pueblos indígenas, no se pueden descartar afectaciones intangibles de orden cultural que sí pueden dar lugar a consulta, conforme el artículo 6 del Convenio 169.

92 LÓPEZ Y MOHR (2014), p. 113

${ }^{93}$ LÓPEZ Y MOHR (2014), p. 113.
} 


\section{BIBLIOGRAFÍA CITADA}

aguilar CAVAllo, GONZAlo (2010): "Emergencia de un derecho constitucional común en materia de pueblos indígenas", en: A.A.V.V., La justicia constitucional y su internacionalización. ¿hacia un lus Constitucionale Commune en américa Latina? (México, UNAM, IIJ), tomo II, pp. 3-84.

ALDUNATE LIZANA, EDUARDO (2010): "La posición de los tratados internacionales en el sistema de fuentes del ordenamiento jurídico chileno a la luz del derecho positivo", en: Revista lus et Praxis (Vol. 16, №2), pp. 185-210.

ANAYA, JAMES (2009): "Informe del Relator Especial sobre los derechos de los pueblos indígenas al Consejo de Derechos Humanos de la AG de Naciones Unidad, 12 período de sesiones. Promoción y protección de todos los derechos humanos, civiles, políticos, económicos, sociales y culturales, incluido el derecho al desarrollo (15.07.2009)". Disponible en: https://www.acnur.org/fileadmin/Documentos/BDL/2010/8057.pdf [visitado el 23 de junio de 2019].

AYLWIN OYARZÚN, JOSÉ (1995): "Derecho Consuetudinario Indígena en el Derecho Internacional, Comparado y en la Legislación Chilena. II Congreso Chileno de Antropología". Disponible en: https://www.aacademica.org/ii.congreso.chileno.de.antropologia/29 [visitado el 24 de junio de 2019].

AYLWIN OYARZÚN, JOSÉ; MEZA-LOPEHANDÍA, MATÍAS Y YAÑEZ FUENZALIDA, NANCY (2013): Los pueblos indígenas y el derecho (Santiago, Observatorio Ciudadano, LOM).

BENHABIB, SHEYLA (2006): Las reivindicaciones de la cultura. Igualdad y diversidad en la era global (Buenos Aires, Katz).

BELTRÂO, JANE FELIPE; MONTEIRO DE BRITO, JOSÉ CLAUDIO; GÓMEZ, ITZIAR; PAJARES, EMILIO; PAREDES, FELIPE Y ZÚÑIGA, YANIRA (2014): Derechos Humanos de los Grupos Vulnerables. Guía de prácticas (Barcelona, DHES, Red de Derechos Humanos y Educación Superior).

BOGDANDY, ARMIN VON; FIX-FIERRO, HÉCTOR Y MORALES ANTONIAZZI, MARIELA (2014): lus constitucionale commune en América Latina, rasgos, potencialidades y desafíos (México, UNAM, MPI, IIDC).

CARMONA CALDERA, CRISTÓBAL (2015): “Hacia una comprensión 'trágica' de los conflictos multiculturales: acuerdos reparatorios, VIF y derecho propio indígena”, en: Revista Chilena de Derecho (Vol. 42, N 3), pp. 975-1001.

(2013): "La aplicación del derecho a consulta del Convenio 169 de la OIT en Chile: hacia una definición de su contenido sustantivo: afectación e instituciones representativas". Disponible en: http://www.unsam.edu.ar/ciep/wp-content/uploads/2013/06/Carmona-Caldera-Tesis.pdf [visitado el 24 de junio de 2019]. 
CLAROS, LUIS Y VIAÑA, JORGE (2009): "La interculturalidad como lucha contrahegemónica. Fundamentos no relativistas para una crítica de la de la cultura", en: A.A.V.V., Interculturalidad crítica y descolonización. Fundamentos para el debate (La Paz, Convenio Andrés Bello), pp. 81-147.

DEFENSORÍA PENAL PÚBLICA -DPP- (2017): " $4^{\circ}$ informe de jurisprudencia sobre Defensa penal de imputados indígenas". Disponible en: http://www.biblio.dpp.cl/biblio/datafiles/InfJurind4.pdf [visitado el 24 de junio de 2019].

(2015): " $3^{\circ}$ informe de jurisprudencia sobre Defensa penal de imputados indígenas". Disponible en: http://www.biblio.dpp.cl/biblio/DataFiles/10283.pdf [visitado el 24 de junio de 2019].

DE MAGLIE, CRISTINA (2012): Los delitos culturalmente motivados ideologías y modelos penales (Madrid, Marcial Pons).

DEL REAL, ALBERTO (2014): El derecho a la identidad cultural (Pamplona, Editorial Aranzadi S.A.).

DíAZ DE VALDÉS, JOSÉ MANUEL (2015): “¿Qué Clase de Igualdad Reconoce el Tribunal Constitucional?”, en: Revista lus et Praxis (Vol. 21, № 2), pp. 317-372.

DíAZ POLANCO, HÉCTOR (2000): "Los Dilemas de la Diversidad", en: Castro, Milka (compilador), Actas XII Congreso internacional de derecho consuetudinario y pluralismo legal: desafíos del tercer milenio (Arica, Universidad de Chile, Universidad de Tarapacá), Vol. II, pp. 1009-1020.

ELÓSEGUI ITXASO, MARÍA (2012): El derecho a la identidad cultural en la Europa del siglo XXI (Navarra, EUNSA).

ESPINOZA COLLAO, ÁLVARO (2017): "El reconocimiento del derecho consuetudinario indígena como derechos humanos: su estado en el derecho chileno moderno", en: Cadernos de Dereito Actual (№ 8), pp. 413-437.

FAUNDES PEÑAFIEL, JUAN JORGE (2019): "Derecho fundamental a la identidad cultural de los pueblos indígenas: un nuevo paradigma en la defensa penal indígena en Chile frente al Estado de Derecho hegemónico", en: Revista Izquierdas (№ 45), pp. 51-78.

(2017A): "Derechos humanos y el reconocimiento de la identidad cultural de los pueblos indígenas en América Latina, en la perspectiva crítica del descentramiento intercultural", en: Olvera, Jorge; Olvera, Julio y Guerrero, Ana Luisa (coordinadores), Los pueblos originarios en los debates actuales de los derechos humanos (México, UNAM, CIAC), pp. 39-60.

(2017B): "Honneth y la demanda por reconocimiento intercultural de los pueblos indígenas", en: Revista Perfiles Latinoamericanos ( $N^{\circ} 49$ ), pp. 303-320.

(2015A): “Convenio N¹69 de la OIT en la Jurisprudencia de la Excelentísima Corte Suprema en Chile. Tendencias y debates en materia de propiedad y derecho al Territorio", en: Colecciones Jurídicas de la Corte Suprema. Disponible en: http://decs.pjud.cl/index.php/informes/informes- 
academicos/62-informes-academicos-indigena/379-tendencias-y-debates-en-materia-depropiedad-y-derecho-al-territorio [visitado el 31 de diciembre de 2018].

(2015B): “Recomprensión intercultural de los derechos humanos. Apuntes para el reconocimiento de los pueblos indígenas en América Latina”, en: Justiça do Direito (Vol. 29, № 1), pp. 108-130.

(2015C): "Pensando un horizonte democrático, pluralista e intercultural para el reconocimiento de los pueblos indígenas en América Latina, desde una relectura crítica a Laclau y Mouffe", en: Revista Chilena de Derecho y Ciencia Política (Vol. 6, Nº 3), pp. 85-121.

(2013): "Pueblos indígenas como titulares de derechos humanos", en: Álvarez, Mario y Cippitani, Roberto (coordinadores), Diccionario Analítico de Derechos Humanos e Integración Jurídica (Roma-Perugia-México, ISEG Istituto per gli Studi Economici e Giuridici), pp. 571-579.

GRIMSON, ALEJANDRO (2012): Los Límites de la cultura. Crítica de las teorías de la identidad (Buenos Aires, Siglo Veintiuno Editores).

HITTERS, JUAN CARLOS (2009): "Control de constitucionalidad y control de convencionalidad. Comparación (Criterios fijados por la Corte Interamericana de Derechos Humanos)", en: Estudios Constitucionales (Año 7, N² 2), pp. 109-128.

HONNETH, AXEL (2006): “Redistribución como reconocimiento: Respuesta a Nancy Fraser", en: FRASER, Nancy y HONNETH, Axel (autores), ¿ Redistribución o reconocimiento? Un debate político-filosófico (Madrid, Morata), pp. 127-133.

KALINSKY, BEATRIZ (2000): Justicia, Cultura y Derecho Penal (B. Aires, Ad-Hoc S.R.L).

MARTíNEZ BULLÉ, VíCTOR (2013): "Estándares internacionales de derechos humanos", en: Álvarez, Mario y Cippitani, Roberto (coordinadores), Diccionario Analítico de Derechos Humanos e Integración Jurídica. (Roma-Perugia-México, ISEG Istituto per gli Studi Economici e Giuridici), pp. 244-247.

NASH ROJAS, CLAUDIO (2008): La Concepción de Derechos Fundamentales en Latinoamérica. Tendencias jurisprudenciales. Tesis de doctorado (Santiago, U. de Chile).

NOGUEIRA ALCALÁ, HUMBERTO (2014): Derechos Fundamentales, bloque constitucional de derechos, diálogo interjurisdiccional y control de convencionalidad (México, Ubijus Editorial).

(1997A): “Los Tratados Internacionales en el Ordenamiento Jurídico Chileno", en: Revista lus et Praxis (Vol. 2, $\mathrm{N}^{\circ}$ 2), pp. 9-72.

(1997B): “El bloque constitucional de derechos: La confluencia del derecho internacional y del derecho constitucional en el aseguramiento y garantía de los derechos fundamentales en América Latina". Disponible en: http://www.jornadasderechopublico.ucv.cl/ponencias/El\%20bloque\%20constitucional\%20de\%20d erechos.pdf [visitado el 1 de octubre de 2018]. 
(2007): "El derecho a la propia imagen como derecho fundamental implícito. Fundamentación y caracterización", en: Revista lus et Praxis (Vol. 13, № 2), pp. 245-285.

NÚNEZ POBLETE, MANUEL (2012): “El derecho de consulta previa en el convenio 169 de la OIT. Notas para su implementación en Chile. Comentario de Manuel Núñez", en: Contesse, Jorge (editor), El Convenio 169 de la OIT. Notas para su implementación en Chile (Santiago, Salesianos Impresores S.A.), pp. 232-240.

PERRONE CAMPOS-MELLO, PATRÍCIA Y FAUNDES PEÑAFIEL, JUAN JORGE (2019): “Constitucionalismo em rede: o direito à identidade cultural dos povos indígenas como filtro hermenêutico para tutela da tradicionalidade da ocupação da terra, mimeografado", en: Anais do VIII Congresso Brasileiro de Direito Socioambiental. Cuaderno de resumos (Vol. 5), pp. 471-482.

ROJAS BASTIDAS, DANIEL (2014): Análisis conceptual del derecho a la tierra de los pueblos indígenas según el derecho internacional. Tesis de grado, Facultad de Derecho, P.U. C. Valparaíso (Santiago, INDH).

RUIZ CHIRIBOGA, OSWALDO (2006): "El derecho a la identidad cultural de los pueblos indígenas y las minorías nacionales: una mirada desde el sistema interamericano", en: Revista Internacional de Derechos Humanos (Vol. 5, Año 3), pp. 43-69.

RUIZ, JUAN CARLOS (2015): "Aproximación a los fundamentos constitucionales del peritaje antropológico", en: Guevara, A., Verona, A. y Vergara, R. (editores), El peritaje antropológico. Entre la reflexión y la práctica (Lima, CICAJ).

SALAS ASTRAín, RICARDO (2003): Ética Intercultural. (Re)lecturas del pensamiento latinoamericano (Santiago, Ediciones UCSH).

STAVENHAGEN, RODOLFO (2004): Derecho internacional y derechos indígenas, en: AYLWIN, José (Editor), Derechos humanos y pueblos indígenas: tendencias internacionales y contexto chileno (Temuco, Instituto de Estudios Indígenas), pp. 15-26.

VERGARA, JORGE; VERGARA ESTÉVEZ, JORGE Y GUNDERMANN, HANS (2012): “Tramas y laberintos: sociología e identidad cultural latinoamericana", en: Revista Atenea (Vol. 506, № 15), pp. 13-27.

VILLEGAS díAZ, MYRNA (2014): "Sistemas Sancionatorios indígenas y Derecho Penal ¿Subsiste el Az Mapu?”, en: Revista Política Criminal (Vol. 9, № 17), pp. 213-247.

VILLEGAS díAZ, MYRNA y MELLA SEGUeL, EDUARDo (2017): Cuando la costumbre se convierte en ley. La cuestión penal y la pervivencia de los sistemas sancionatorios indígenas en Chile (Santiago, LOM).

\section{JURISPRUDENCIA CITADA}

BÁMACA VelÁsqueZ VS. GUATEMALA (2000): Corte Interamericana de Derechos Humanos. Sentencia de

25 de noviembre de 2000 (Fondo), en:
http://www.corteidh.or.cr/docs/casos/articulos/Seriec_70_esp.pdf. 
COMUNIDAD (SUMO) AWAS TIGNI CON NICARAGUA (2001): Corte Interamericana de Derechos Humanos, 31 de agosto de 2001 (Fondo, reparaciones, costas), en: http://www.corteidh.or.cr/docs/casos/articulos/Seriec_79_esp.pdf.

MASACRE PLAN DE SÁNCHEZ CON GUATEMALA (2004): Corte Interamericana de Derechos Humanos, 29 de abril de 2004. (Fondo), en: http://www.corteidh.or.cr/docs/casos/articulos/seriec_105_esp.pdf.

CORTE CONSTITUCIONAL DE COLOMBIA, SENTENCIA T-778/05, "Acción de tutela transitoria. Derecho de representación de indígena en cargos de elección popular" en: http://www.corteconstitucional.gov.co/relatoria/2005/T-778-05.htm.

COMUNIDAD INDÍGENA YAKYE AXA CON PARAGUAY (2005): Corte Interamericana de Derechos Humanos. Sentencia de 17 de junio de 2005. (Fondo, Reparaciones y Costas), en: http://www.corteidh.or.cr/docs/casos/articulos/seriec_125_esp.pdf.

COMUNIDAD INDÍGENA MOIWANA CON SURINAM (2005): Corte Interamericana de Derechos Humanos. Sentencia de 15 de junio de 2005. (Excepciones Preliminares, Fondo, reparaciones y Costas), en: http://www.corteidh.or.cr/docs/casos/articulos/seriec_124_esp1.pdf.

COMUNIDAD INDÍGENA SAWHOYAMAXA CON PARAGUAY (2006): Corte Interamericana de Derechos Humanos. Sentencia de 29 de marzo de 2006 (Fondo, Reparaciones y Costas), en: http://www.corteidh.or.cr/docs/casos/articulos/seriec_146_esp2.pdf.

PUEBLO SARAMAKA CON SURINAM (2007): Corte Interamericana de Derechos Humanos, Sentencia del 28 de noviembre de 2007 (Excepciones Preliminares, Fondo, Reparaciones y Costas), en: http://www.corteidh.or.cr/docs/casos/articulos/seriec_172_esp.pdf.

REQUERIMIENTO DE INAPLICABILIDAD DEL JUEZ PRESIDENTE DEL JUZGADO DE FAMILIA DE PUDAHUEL, SOBRE LA APLICACIÓN DEL ARTÍCULO 206 DEL CÓDIGO CIVIL (2009): Tribunal Constitucional 29 de septiembre de 2009 (requerimiento), en: http://www.tribunalconstitucional.cl/expedientes?rol=1340.

ALEJANDRO PAPIC CON COMUNIDAD INDÍGENA AYMARA CHUZMIZA Y USMAGAMA (2009): Corte Suprema 25 de noviembre de 2009 (Recurso de casación, forma y fondo, civil), en: https://suprema.pjud.cl/SITSUPPORWEB/DownloadFile.do?TIP_Documento=3\&TIP_Archivo=3\&C OD_Opcion=1\&COD_Corte=1\&CRR_IdTramite=517143\&CRR_IdDocumento=300721.

LINCONAO HUIRCAPAN FRANCISCA CON SOCIEDAD PALERMO (2009): Corte Suprema 30 de noviembre de 2009 (Recurso protección, 1ra. Instancia, apelación), en: https://suprema.pjud.cl/SITSUPPORWEB/DownloadFile.do?TIP_Documento=3\&TIP_Archivo=3\&C OD_Opcion=1\&COD_Corte=1\&CRR_IdTramite=647053\&CRR_IdDocumento=385747.

REQUERIMIENTO DE INAPLICABILIDAD POR INCONSTITUCIONALIDAD, RESPECTO DE LOS ARTÍCULOS 206 DEL CÓDIGO CIVIL Y 5 TRANSITORIO, INCISO CUARTO FINAL DE LA LEY 19.585 (2011): Tribunal Constitucional 30 de agosto de 2011 (requerimiento), en: http://www.tribunalconstitucional.cl/expedientes?rol=1563. 
REQUERIMIENTO DE INAPLICABILIDAD POR INCONSTITUCIONALIDAD, RESPECTO DE LOS ARTÍCULOS 206 DEL CÓDIGO CIVIL Y 5 O TRANSITORIO, INCISO CUARTO FINAL DE LA LEY 19.585 (2011): Tribunal Constitucional 1 de septiembre de 2011 (requerimiento), en: http://www.tribunalconstitucional.cl/expedientes?rol=1537.

REQUERIMIENTO DE INAPLICABILIDAD POR INCONSTITUCIONALIDAD DEL SR JUEZ DEL JUZGADO DE FAMILIA DE PUDAHUEL, RESPECTO DEL ARTÍCULO 206 DEL CÓDIGO CIVIL (2011): Tribunal Constitucional 1 de septiembre de 2011 (requerimiento), en: http://www.tribunalconstitucional.cl/expedientes?rol=1656.

ARellano almonacid VS. CHILE (2012): Corte de Apelaciones de Rancagua, de 14 de enero de 2013 (Casación, forma fondo, penal) en: http://www.pjud.cl.

REMINGUAL LEMUI CON MUNICIPALIDAD DE OSORNO (2012): Corte Suprema 25 de septiembre de 2013 (Casación, fondo, apelación), en: https://suprema.pjud.cl/SITSUPPORWEB/DownloadFile.do?TIP_Documento=3\&TIP_Archivo=1\&C OD_Opcion=1\&COD_Corte=1\&CRR_IdTramite=1217617\&CRR_IdDocumento=801444.

PUEBLO INDÍGENA KICHWA DE SARAYAKU CON ECUADOR (2012): Corte Interamericana de Derechos Humanos, de 27 de junio de 2012. (Fondo y reparaciones), en: http://corteidh.or.cr/docs/casos/articulos/seriec_245_esp.pdf.

COMUNIDAD INDÍGENA ANTILAFQUEN DE HUENTETIQUE CON COMISIÓN REGIONAL DEL MEDIO AMBIENTE DE LOS LAGOS (2012): Corte Suprema 22 de marzo de 2012 (Recurso de protección, apelación), en: https://suprema.pjud.cl/SITSUPPORWEB/DownloadFile.do?TIP_Documento=3\&TIP_Archivo=3\&C OD_Opcion=1\&COD_Corte=1\&CRR_IdTramite=778618\&CRR_IdDocumento=480950.

COMUNIDAD INDÍGENA HUENCHULLÁN CON MINISTRO DE ENERGíA JORGE BUNSTER (2013): Corte Suprema 17 de enero de 2013 (Recurso de protección, 1ra. Instancia, apelación), en: https://suprema.pjud.cl/SITSUPPORWEB/DownloadFile.do?TIP_Documento=3\&TIP_Archivo=3\&C OD_Opcion=1\&COD_Corte=1\&CRR_IdTramite=778618\&CRR_IdDocumento=480950.

MINISTERIO PÚBLICO CON MOISÉS MALIQUeO (2013): Tribunal Oral en lo Penal de Temuco 17 de agosto de 2013 (Sentencia Tribunal oral en lo Penal) en: http://www.pjud.cl.

HERMINIA TOROCO HERRERA Y OTRO CON SOCIEDAD INVERSIONES E INMOBILIARIA VILLA NUEVA S.A. (2013): Corte Suprema 26 de septiembre de 2013 (Recurso de protección, apelación), en: https://suprema.pjud.cl/SITSUPPORWEB/DownloadFile.do?TIP_Documento=3\&TIP_Archivo=1\&C OD_Opcion=1\&COD_Corte=1\&CRR_IdTramite=1218243\&CRR_IdDocumento=802044.

CODELCO CHILE DIVISIÓN CHUQUICAMATA CON DIRECCIÓN REGIONAL Y NACIONAL DE AGUAS (2014): Corte Suprema 15 de mayo de 2014 (Recurso de casación, fondo, civil) en: https://suprema.pjud.cl/SITSUPPORWEB/DownloadFile.do?TIP_Documento=3\&TIP_Archivo=1\&C OD_Opcion=1\&COD_Corte=1\&CRR_IdTramite=1404600\&CRR_IdDocumento=969581.

SOLICITUD DE INCONSTITUCIONALIDAD DEL ARTÍCULO $1^{\circ}$, NUMERALES 20, 3, LETRA C) Y 48 DEL PROYECTO DE LEY QUE "MODIFICA EN EL ÁMBITO DE LA SUSTENTABILIDAD DE RECURSOS HIDROBIOLÓGICOS, ACCESO A LA ACTIVIDAD PESQUERA INDUSTRIAL Y ARTESANAL Y REGULACIONES PARA LA INVESTIGACIÓN Y FISCALIZACIÓN, LA LEY GENERAL DE 
PESCA Y ACUICULTURA CONTENIDA EN LA LEY No 18.892 Y SUS MODIFICACIONES (2014): Tribunal Constitucional 23 de enero de 2013, en: http://www.tribunalconstitucional.cl/expediente?rol=2387wsdefrtg.

REQUERIMIENTO DE INAPLICABILIDAD POR INCONSTITUCIONALIDAD PRESENTADO POR INVERSIONES TAMA S.A. RESPECTO DE LOS ARTÍCULOS 54, 55, 56 Y 58 DE LA LEY N 19.253 (2015): Tribunal Constitucional 24 de diciembre de 2015. en file:///C:/Users/JUAN/Downloads/3204.pdf.

COMPAÑÍA MINERA CERRO COLORADO CON FISCO DE CHILE (2016): Corte Suprema 4 de mayo de 2016 (Casación de fondo), en: https://suprema.pjud.cl/SITSUPPORWEB/DownloadFile.do?TIP_Documento=3\&TIP_Archivo=1\&C OD_Opcion=1\&COD_Corte=1\&CRR_IdTramite=2154009\&CRR_IdDocumento=1679743.

PUEBLO INDÍGENA XUCURU Y OTROS CON BRASIL (2018): Corte Interamericana de Derechos Humanos 5 de febrero 2005. (Excepciones preliminares, fondo). En http://www.corteidh.or.cr/docs/casos/articulos/seriec_346_esp.pdf.

\section{NORMAS JURÍDICAS CITADAS}

DECLARACIÓN AMERICANA SOBRE LOS DERECHOS DE LOS PUEBLOS INDÍGENAS (OEA 15 de junio de 2016).

DECLARACIÓN DE NACIONES UNIDAS PARA LOS DERECHOS DE LOS PUEBLOS INDÍGENAS (N.U., 13 de septiembre de 2007).

DECLARACIÓN UNIVERSAL DE LA UNESCO SOBRE LA IDENTIDAD CULTURAL DEL AÑO 2001 (UNESCO, 2 de noviembre de 2001).

CONVENCIÓN PARA la SAlVAgUaRdia del PATRIMONIO CUltuRAL INMATERIAL (Paris, 23 de septiembre de 2003).

CONVENCIÓN AMERICANA DE DERECHOS HUMANOS (1969), 21 de agosto de 1990. Diario Oficial 5 de enero de 1991.

CONVENIO 169 DE LA OIT (1989), 15/09/2008, D.S. N²36, 2 de octubre de 2008. Diario Oficial 14 de octubre de 2008.

LEY No19.253 que Establece normas sobre protección, fomento y desarrollo de los indígenas, y crea la Corporación Nacional de Desarrollo Indígena. Diario Oficial 5 de octubre de 1993.

PACTO INTERNACIONAL DE DERECHOS CIVILES Y POLÍTICOS (1966), 10 de febrero de 1972, D.S. № 788-1976. Diario Oficial 24 de abril de 1989.

PACTO INTERNACIONAL DE DERECHOS ECONÓMICOS, SOCIALES Y CULTURALES (1966), 10 de febrero de 1972, D.S. 326, 27 de mayo de 1989. Diario Oficial 27 de mayo de 1989. 